\title{
Comparison of albicans vs. non-albicans candidemia in French intensive care units
}

\author{
Olivier Leroy*1, Jean-Paul Mira2,3, Philippe Montravers4,5, Jean-Pierre Gangneux6,7, Olivier Lortholary 8,9,10 for the \\ AmarCand Study Group
}

\begin{abstract}
Introduction: Candidemia raises numerous therapeutic issues for intensive care physicians. Epidemiological data that could guide the choice of initial therapy are still required. This analysis sought to compare the characteristics of intensive care unit (ICU) patients with candidemia due to non-albicans Candida species with those of ICU patients with candidemia due to Candida albicans.

Methods: A prospective, observational, multicenter, French study was conducted from October 2005 to May 2006. Patients exhibiting candidemia developed during ICU stay and exclusively due either to one or more non-albicans Candida species or to C. albicans were selected. The data collected included patient characteristics on ICU admission and at the onset of candidemia.

Results: Among the 136 patients analyzed, 78 (57.4\%) had candidemia caused by C. albicans. These patients had earlier onset of infection (11.1 \pm 14.2 days after ICU admission vs. $17.4 \pm 17.7, p=0.02$ ), higher severity scores on ICU admission (SOFA: $10.4 \pm 4.7$ vs. $8.6 \pm 4.6, p=0.03$; SAPS II: $57.4 \pm 22.8$ vs. $48.7 \pm 15.5, P=0.015$ ), and were less often neutropenic ( $2.6 \%$ vs. $12 \%, p=0.04$ ) than patients with candidemia due to non-albicans Candida species.

Conclusions: Although patients infected with Candida albicans differed from patients infected with non-albicans Candida species for a few characteristics, no clinical factor appeared pertinent enough to guide the choice of empirical antifungal therapy in ICU.
\end{abstract}

\section{Introduction}

The importance of fungal infections in Intensive Care Units (ICUs) was recently underlined by the EPIC Study II, since fungal agents represented $19 \%$ of positive isolates [1]. Moreover, candidemia still raises numerous therapeutic issues to Intensive Care physicians. The relationship between prognosis and early initiation of the adequate antifungal therapy is well established [2-4]. Ideally, adequate therapy must be started much before candidemia is ascertained, therefore much before the causative Candida species is identified and its susceptibility to antifungals is known. Broad spectrum antifungals have enriched the therapeutic arsenal in the past few years. The above therapeutic constraints might tempt clinicians to use these agents widely. However, apart from financial aspects, an excessive usage could become dele-

* Correspondence: oleroy@ch-tourcoing.fr

1 Service de Réanimation Médicale et des Maladies Infectieuses, Centre Hospitalier Gustave Dron, 135 rue du Président Coty, 59208 Tourcoing, France Full list of author information is available at the end of the article terious by resulting in the selection of strains with reduced susceptibility.

In a prospective multicenter observational study named AmarCand performed to assess the current epidemiology, management and prognosis of invasive Candida infections in French ICUs, we demonstrated that $95.6 \%$ of C. albicans strains were susceptible to fluconazole whereas only $68 \%$ of non-albicans Candida were susceptible [5]. Thus, among data that could guide the choice of initial therapy, the availability of elements that would allow a binary distinction, with sufficient liability, between albicans or non-albicans Candida could represent an interesting first step.

In the present paper, the characteristics of patients from the AmarCand study, on ICU admission and at the onset of candidemia, are described according to whether candidemia was due to an albicans or a non-albicans Candida strain. 


\section{Materials and methods}

The AmarCand ("Analyse du Management en Anesthésie et Réanimation des Candidoses invasives") study

This study has already been described in two publications from the Group [5,6]. Briefly, AmarCand was a prospective, multicentre, national and observational study. Adult ICU patients with invasive Candida infection requiring a systemic antifungal therapy were included. Criteria used for diagnosis were those proposed in 2002 by the members of the European Organization for Research and Treatment of Cancer/Invasive Fungal Infections Cooperative Group and the National Institute of Allergy and Infectious Diseases Mycoses Study Group [7]. In accordance with the French law, approval of an Ethics Committee was not required. However, all patients gave informed consent to participate. Approval of the "Commission Nationale de l'Informatique et des Libertés" was obtained, ensuring that patient data were kept confidential according to the French regulation.

For each episode of invasive Candida infection, demographic characteristics, underlying diseases, current hospitalization, severity of illness, and process of care were recorded by each investigator on a standardized report form. Identification of the Candida isolates was performed in mycology and microbiology laboratories using the routine methods of each hospital. Isolates were classified as susceptible (S), susceptible-dose dependent (S$\mathrm{DD})$, or resistant (R) to antifungals according to CLSI interpretive categories [8].

\section{Comparison of candidemia due to Candida albicans vs. non- albicans Candida species}

For this comparison, we identified patients from the AmarCand study with a candidemia acquired in ICU and exclusively due either to $C$. albicans or to one or more non-albicans Candida species. These groups were compared for the patients' characteristics on ICU admission and at the onset of candidemia.

\section{Statistics}

Data were analyzed using $\mathrm{SAS}^{\circ} 8.2$ (SAS Institute Inc., Cary, NC, USA). Variables were expressed as mean values \pm standard deviation for numerical variables and as frequencies and percentages for categorical variables. Groups were compared using the Chi-square and Fisher's exact tests. Continuous variables were compared using the Student's $t$ test. Statistical significance was accepted at the $5 \%$ level.

\section{Results}

A total of 271 evaluable patients were included in the AmarCand study between October 2005 and May 2006. A total of 101 ICUs participated: 44 (43.6\%) medico-sur- gical ICUs, 28 (27.7\%) medical ICUs and 29 (28.7\%) surgical ICUs.

For the purposes of the present paper, we excluded from the 271 evaluable patients: 87 patients with invasive candidiasis but no candidemia, 13 patients with mixed candidemia due to albicans and non-albicans Candida species, and 35 patients who acquired candidemia before admission in ICU. Therefore, 136 patients were included in the present analysis.

Candidemia was due to C. albicans in 78 (57.4\%) patients. It was due to non-albicans Candida species in 58 (42.6\%) patients. In total, 63 non-albicans Candida isolates were identified: C. glabrata $\mathrm{n}=25, C$. parapsilosis $\mathrm{n}=12$, C. tropicalis $\mathrm{n}=9$, C. kefyr $\mathrm{n}=4$, C. krusei $\mathrm{n}=6$ and other species $\mathrm{n}=7$. In vitro susceptibility to fluconazole was determined for 112 isolates. The rate of fluconazole-R or S-DD Candida was 3.3\% (2/61) for C. albicans, $50.0 \%$ (10/20) for C. glabrata, 18.2\% (2/11) for C. parapsilosis, $100 \%$ (3/3) for C. krusei, 25\% (2/8) for C. tropicalis, $0 \%(0 / 4)$ for $C$. kefyr, and $40 \%(2 / 5)$ for the remaining Candida species. Susceptibility to fluconazole was determined for 61 episodes of candidemia due to C. albicans and for 47 episodes due to non-albicans Candida species. The rate of episodes due to a fluconazole-R or S-DD Candida was $3.3 \%$ and $38.3 \%$, respectively $(P<0.0001)$.

Table 1 provides the major characteristics of patients on admission in ICU. The only significant differences observed between both types of candidemia were the Simplified Acute Physiology Score II (SAPS II) and the Sepsis-related Organ Failure Assessment (SOFA) score, which were significantly higher in case of infection with C. albicans.

The time from ICU admission to onset of candidemia was $13.8 \pm 16.1$ days. It was significantly shorter in the case of candidemia due to C. albicans: $11.1 \pm 14.2$ days vs. $17.4 \pm 17.7$ days with non-albicans Candida species $(P=$ 0.02). Candidemia developed within six days after admission in ICU for 59 patients. Such an early infection was significantly more frequent when candidemia was due to C. albicans than when it was due to non-albicans Candida species (40/78 vs. $19 / 58, P=0.03)$. Neutropenia (absolute neutrophil count $<500$ cells $/ \mathrm{mm}^{3}$ ) was concomitant to candidemia in nine patients. It was significantly more frequent when candidemia was caused by non-albicans Candida species than when it was caused by C. albicans $(7 / 58$ vs. $2 / 78, P=0.04)$.

The main features of the patients' care at the onset of candidemia are shown in Table 2. There were no significant differences between the two patient groups, notably for previous exposure to azole agents.

\section{Discussion}

In this study, the characteristics of patients with candidemia caused by non-albicans Candida species versus 
Table 1: Clinical characteristics of patients on admission to intensive care unit

\begin{tabular}{|c|c|c|c|c|}
\hline & $\begin{array}{l}\text { Total } \\
N=136\end{array}$ & $\begin{array}{l}\text { Candidemia due to } \text { C. albicans } \\
N=78\end{array}$ & $\begin{array}{l}\text { Candidemia due to non-albicans } \\
\text { Candida species } \\
\mathrm{N}=\mathbf{5 8}\end{array}$ & $P$ value \\
\hline Age (years) & $62.1 \pm 14.9$ & $61.0 \pm 17.2$ & $63.5 \pm 11.1$ & 0.32 \\
\hline Male gender & $84(61.8)$ & $45(57.7)$ & $39(67.2)$ & 0.26 \\
\hline SAPS II & $53.8 \pm 20.4$ & $57.4 \pm 22.8$ & $48.7 \pm 15.5$ & 0.015 \\
\hline SOFA & $9.6 \pm 4.7$ & $10.4 \pm 4.7$ & $8.6 \pm 4.6$ & 0.03 \\
\hline Underlying disease* & & & & 0.35 \\
\hline Absent or nonfatal & $63(46.3)$ & $37(47.4)$ & $26(44.8)$ & \\
\hline Ultimately fatal & $58(42.7)$ & $35(44.9)$ & $23(39.7)$ & \\
\hline Rapidly fatal & $15(11.0)$ & $6(7.7)$ & $9(15.5)$ & \\
\hline Chronic renal failure & $26(19.1)$ & $16(20.5)$ & $10(17.2)$ & 0.63 \\
\hline Type 1 diabetes mellitus & $16(11.8)$ & $8(10.3)$ & $8(13.8)$ & 0.52 \\
\hline Solid neoplastic tumor & $32(23.5)$ & $19(24.4)$ & $13(22.4)$ & 0.79 \\
\hline Hematological malignancy & $7(5.1)$ & $4(5.1)$ & $3(5.2)$ & 0.99 \\
\hline Immunosuppression & $28(20.6)$ & $15(19.2)$ & $13(22.4)$ & 0.65 \\
\hline Corticotherapy & $10(7.4)$ & $3(3.8)$ & $7(12.1)$ & 0.06 \\
\hline HIV infection & $2(1.5)$ & $2(2.6)$ & 0 & 0.17 \\
\hline Cancer chemotherapy & $10(7.4)$ & $5(6.4)$ & $5(8.6)$ & 0.78 \\
\hline Organ transplantation & $5(3.7)$ & $2(2.6)$ & $3(5.2)$ & 0.50 \\
\hline Immunosuppressant therapy & $4(2.9)$ & $2(2.6)$ & $2(3.4)$ & 0.88 \\
\hline Intravenous drug use & $2(1.5)$ & $1(1.3)$ & $1(1.7)$ & 0.83 \\
\hline Neutropenia $\left(<500 / \mathrm{mm}^{3}\right)$ & $9(6.6)$ & $2(2.6)$ & $7(12.1)$ & 0.04 \\
\hline
\end{tabular}

Results are expressed as mean \pm SD values or numbers (\%) of patients.

HIV: human immunodeficiency virus; SAPS: simplified acute physiology score; SOFA: sepsis-related organ failure assessment

${ }^{*}$ Classified according to the criteria proposed by McCabe and Jackson [17]

Candida albicans in ICU were compared. The main result is that only a few significant differences were observed: severity of the disease, the time to candidemia onset and the rate of underlying neutropenia. So, we did not identify a parameter pertinent enough to allow a binary distinction between albicans or non-albicans Candida and to guide the choice of empirical antifungal therapy.

Studies that compare the epidemiological characteristics of patients with candidemia caused by non-albicans Candida species versus Candida albicans are scarce and their results are disparate.

Three studies included patients who were not all adults and/or not all admitted in ICU. Cheng et al. retrospectively analyzed 130 cases of fatal candidemia due to either a C. albicans $(\mathrm{n}=68)$ or a non-albicans $C$. species $(\mathrm{n}=62)$ [9]. Multivariate analyses showed that factors independently associated with $C$. albicans infection were the age $\geq 65$ years, hyperleukocytosis $\left(>15,000\right.$ cells $\left./ \mathrm{mm}^{3}\right)$, and immunosuppressant therapy. Shorr et al. retrospectively analyzed the files of 245 candidemic patients from two different hospitals [10]. C. albicans represented 52\% of the causative species. None of the parameters describing severity of the disease and previous exposition to azole agents was significantly predictive of a candidemia due to a non-albicans Candida strain. The third report arises from a large registry of 2,019 patients included between July 2004 and March 2008 in 23 North American hospitals [11]. Underlying hematological malignancy and bone marrow grafting were less common in patients with a candidemia due to $C$. albicans. Prior antifungal therapy was reported in $43 \%$ of the 2,019 patients. It was significantly less frequent in patients with $C$. albicans infection (38.8\% vs. $46.5 \%, P<0.001$ ).

Three other studies were performed exclusively in ICU. In Australia Playford et al. carried out a three-year prospective, national survey [12]. A total of 179 episodes of candidemia were studied, of which $62 \%$ were related to $C$. albicans. Factors associated independently with a candidemia not related to $C$. albicans were recent intraabdominal surgery and recent exposition to systemic antifungal therapy. Chow et al. compared 79 patients 
Table 2: Main features of patients' care at the onset of candidemia

\begin{tabular}{|c|c|c|c|c|}
\hline & $\begin{array}{l}\text { Total } \\
\mathrm{N}=136\end{array}$ & $\begin{array}{l}\text { Candidemia due to } \\
\text { C. albicans } \\
\mathrm{N}=78\end{array}$ & $\begin{array}{l}\text { Candidemia due to non-albicans } \\
\text { Candida species } \\
\mathrm{N}=\mathbf{5 8}\end{array}$ & $P$ value \\
\hline Recent surgery ( $<3$ months) & $75(55.1)$ & $43(55.1)$ & $32(55.2)$ & 0.99 \\
\hline Intra-abdominal & $56(41.2)$ & $32(41.0)$ & $24(41.6)$ & 0.95 \\
\hline Vascular & $9(6.6)$ & $6(7.7)$ & $3(5.2)$ & 0.54 \\
\hline Time from surgery to candidemia (days) & $23.6 \pm 20.7$ & $22.6 \pm 19.3$ & $25.0 \pm 22.7$ & 0.62 \\
\hline Invasive mechanical ventilation & $106(77.9)$ & $62(79.5)$ & $44(75.9)$ & 0.61 \\
\hline CVC & $122(89.8)$ & $68(87.2)$ & $54(93.2)$ & 0.26 \\
\hline Time from CVC placement to candidemia (days) & $15.2 \pm 16.9$ & $13.1 \pm 14.9$ & $17.8 \pm 18.9$ & 0.13 \\
\hline UC & $122(89.8)$ & $68(87.2)$ & $54(63.2)$ & 0.26 \\
\hline Time from UC placement to candidemia (days) & $16.4 \pm 17.0$ & $14.7 \pm 16.7$ & $18.6 \pm 17.4$ & 0.22 \\
\hline Prior antibiotherapy & $84(61.8)$ & $48(61.5)$ & $36(62.1)$ & 0.95 \\
\hline $\begin{array}{l}\text { Duration of antibiotherapy before candidemia } \\
\text { (days) }\end{array}$ & $18.2 \pm 13.5$ & $17.8 \pm 14.4$ & $18.7 \pm 12.4$ & 0.77 \\
\hline Previous exposure to azole agents & $23(16.9)$ & $11(14.1)$ & $12(20.7)$ & 0.31 \\
\hline Vasoactive drug use & $31(22.8)$ & $20(25.6)$ & $11(19.0)$ & 0.36 \\
\hline
\end{tabular}

Results are expressed as mean \pm SD values or numbers (\%) of patients. CVC: central venous catheter; UC: urinary catheter

with candidemia due to C. albicans and 67 patients with candidemia due to non-albicans Candida species [13]. Previous exposition to azole agents, duration of central venous catheter implantation and the number of antimicrobial agents per day were associated with non-albicans Candida infection in multivariate analyses. Conversely, the duration of parenteral nutrition was associated with a reduced risk of non-albicans Candida infection. Finally, 189 candidemic patients (C. albicans: 56\%) were included in the international, multicenter, retrospective study of Holley et al. [14]. Factors associated independently with candidemia due to non-albicans Candida species were female gender and duration of central venous catheter implantation using multivariate analysis.

Our results obtained in 136 episodes of candidemia contrast with those of the three above studies performed in ICU [12-14]. Indeed, neither intra-abdominal surgery, previous exposure to azole agents, duration of central venous catheter implantation, nor female gender were associated with non-albicans Candida infection. Our results are however in line with those of Shorr et al., who could not identify clearly any parameter associated with the Candida species causative of candidemia [10].

Several consensual recommendations for the management of invasive Candida infections have been published in the last few years. In the French recommendations, which go back to 2004, the algorithm takes into account previous exposition to azole agents [15]. Empirical treatment based on fluconazole is proposed for patients who had not been exposed previously to azole agents. The 2009 North American recommendations propose empirical broad-spectrum treatment with an echinocandin for all ICU patients irrespective of previous exposition to azole agents [16]. Both recommendations propose to continue therapy with de-escalation if the causative strain is susceptible to fluconazole. Our results showing a high incidence $(38.3 \%)$ of fluconazole non-susceptible Candida, and no pertinent parameter able to predict the species of causative Candida suggest that, in France and probably the rest of Europe, the use of the North American recommendation may now be more adequate. The use of echinocandin as first-line treatment (before the identification of the causative Candida strain and determination of its susceptibility) for all ICU patients suffering from candidemia could decrease the incidence of inappropriate empirical antifungal therapy and thus improve outcome of patients with such invasive candidiasis [3]. A de-escalation could be proposed in patients who are clinically stable when minimum inhibitory concentration (MIC) to fluconazole is $\leq 8 \mathrm{mg} / \mathrm{L}$ [16].

\section{Conclusions}

Comparison of the characteristics of ICU patients with candidemia caused by non-albicans Candida species versus Candida albicans did not allow identifying any parameter pertinent enough to guide the choice of empirical antifungal therapy. 


\section{Key messages}

- Characteristics of patients with candidemia caused by non-albicans Candida species versus Candida albicans are quite similar at the onset of candidemia.

- Empiric antifungal therapy should be based on a broad-spectrum treatment effective against non-albicans Candida species and Candida albicans.

\section{Abbreviations}

AmarCand: "Analyse du Management en Anesthésie et Réanimation des Candidoses invasives"; C: Candida; CVC: central venous catheter; HIV: human immunodeficiency virus; ICU: intensive care unit; MIC: minimum inhibitory concentration; SAPS: simplified acute physiology score; SOFA: sepsis-related organ failure assessment; UC: urinary catheter

\section{Competing interests}

OLer has received speaking honoraria from Pfizer, MSD, Astellas, Schering Plough; JPM has received speaking honoraria from Pfizer, MSD, Astellas; PM has received speaking honoraria from Pfizer, MSD, Astellas, Astra Zeneca, Eli Lilly; JPG has received speaking honoraria from Pfizer, MSD, Astellas, Schering Plough, Gilead Sciences; and OLor has received speaking honoraria from Pfizer, MSD, Astellas, Schering Plough, and Gilead Sciences.

The research, including the article-processing charge, was funded in full by Merck Sharpe \& Dohme-Chibret, France.

\section{Authors' contributions}

OLer contributed to the design of the study and wrote the manuscript. JPM contributed to the design of the study and contributed to the final revision of the manuscript for important intellectual content. PM contributed to the design of the study and contributed to the final revision of the manuscript for important intellectual content. JPG contributed to the design of the study and contributed to the final revision of the manuscript for important intellectual content. OLor contributed to the design of the study and contributed to the final revision of the manuscript for important intellectual content. All the authors read and approved the final manuscript.

\section{Acknowledgements}

The authors are grateful to all physicians who participated in this study (the AmarCand Study Group, see below). They thank P. Devos (Département de biostatistiques, CHRU Lille. 59 - France) who analyzed the data and thank Marina Varastet for helping to prepare this manuscript. Marina Varastet is employed by ClinSearch (Medical Writing Department, Bagneux - France), which was contracted by the funding sponsor for manuscript editing

The whole publication activity was overseen by an academic, study-specific scientific committee (the authors). This committee includes independent authors who are not governed by the funding sponsor. The funding sponsor had the opportunity to review the manuscript but not the authority to change any of its aspects.

The AmarCand Study Group (ICU physicians): Drs. Allaouchiche (Lyon), Amigues (Montpellier), Ausseur (Saint Herblain), Azoulay (Paris), Badet (Lyon), Baldesi (Aix-en-Provence), Bastien (Bron), Baudin (Paris), Bayle (Lyon), Bazin (Clermont-Ferrand), Benayoun (Clichy), Blondeau (Roubaix), Bodin (Paris), Bollaert (Nancy), Bonadona (La Tronche), Bonnaire (Aulnay Sous Bois), Bonnivard (Montauban), Borne (Paris), Brabet (Montpellier), Branche (Lyon), Braud (Rouen), Bret (Lyon), Bretonnière (Nantes), Brocas (Evry), Brun (Bron), Bruneel (Versailles), Canevet (Armentières), Cantais (Toulon Armées), Carlet (Paris), Charbonneau (Caen), Charles (Dijon), Chastagner (Chamberry), Corne (Montpellier), Courte (Saint-Brieuc), Cousson (Reims), Cren (Morlaix), Diconne (Saint Etienne), Drouet (Saint-Denis), Dube (Angers), Duguet (Paris), Dulbecco (Antibes), Dumenil (Clamart), Dupont (Amiens), Durand (Grenoble), Durand-Gasselin (Toulon), Durocher (Lille), Fangio (Poissy), Fattouh (Mulhouse), Favier (Metz Armées), Fieux (Paris), Fleureau (Pessac), Freys (Strasbourg), Fulgencio (Paris), Gally (Mulhouse), Garnaud (Orléans), Garot (Tours), Gilhodes (Créteil), Girault (Rouen), Gouin (Marseille), Gouin (Rouen), Guidon (Marseille), Hérault (Grenoble), Hyvernat (Nice), Jobard (Monaco), Jospe (Saint Etienne), Kaidomar (Fréjus), Karoubi (Bobigny), Kherchache (Agen), Lacherade (Poissy), Lakermi (Paris), Lambiotte (Maubeuge), Lamia (Le Kremlin-Bicêtre), Lasocki (Paris), Launoy (Strasbourg), Le Guillou (Paris), Lefort (Saint-Denis), Lefrant (Nîmes), Lemaire
(Roubaix), Lepape (Pierre-Bénite), Lepoutre (Lomme), Leroy (Lille), Leroy (Tourcoing), Loriferne (Bry-sur-Marne), Mahe (Nantes), Mandin (Gap), Marighy (SaintDenis), Mathieu (Lille), Mathonnet (Paris), Megarbane (Paris), Mercat (Angers), Michel (Saint Herblain), Michelet (Marseille), Mimoz (Poitiers), Mohammedi (Lyon), Mouquet (Paris), Mourvillier (Paris), Navellou (Besançon), Novara (Paris), Obadia (Montreuil), Perrigault (Montpellier), Perrin (Marseille), Petit (Valence), Poussel (Metz), Rahmani (Strasbourg), Renard (La Roche sur Yon), Robert (Poitiers), Robert (Lyon), Saliba (Villejuif), Sannini (Marseille), Santré (Annecy), Seguin (Rennes), Souweine (Clermont-Ferrand), Trouillet (Paris), Valentin (Besançon), Volatron (Rennes), Voltz (Vandoeuvre les Nancy), Winer (Saint Pierre), and Winnock (Bordeaux).

\section{Author Details}

1Service de Réanimation Médicale et des Maladies Infectieuses, Centre Hospitalier Gustave Dron, 135 rue du Président Coty, 59208 Tourcoing, France, 2Service de Réanimation Médicale, Hôpital Cochin, 27 rue du Faubourg Saint Jacques, Assistance publique, Hôpitaux de Paris, 75014 Paris, France, 3Université Paris Descartes, INSERM U567, 12 rue de l'école de Médecine, 75006 Paris, France, ${ }^{4}$ Département d'Anesthésie-Réanimation Chirurgicale, Centre Hospitalier Universitaire Bichat-Claude Bernard, 46 rue Henri Huchard, Assistance publique, Hôpitaux de Paris, 75018 Paris, France, 5Université Paris VII, 16 rue Henri Huchard, 75018 Paris, France, 6 Laboratoire de ParasitologieMycologie, Centre Hospitalier Universitaire Pontchallou, 2 rue Henri Le Guilloux 35000 Rennes, France, ${ }^{7} E A$ SeRAIC 4427, IRSET-Institut de recherche en santé, Environnement et Travail, Université Rennes 1, 2 avenue du Professeur Léon Bernard, 35043 Rennes, France, 8 Université Paris Descartes, 12 rue de l'école de Médecine, 75006 Paris, France, ${ }^{9}$ Centre d'infectiologie Necker-Pasteur, CHU Necker-Enfants-Malades, 149 rue Sèvres, Assistance publique, Hôpitaux de Paris, 75015 Paris, France and 10Institut Pasteur, 211 rue Vaugirard, 75015 Paris, Centre National de Référence de Mycologie et Antifongiques, CNRS URA3012, France

Received: 3 March 2010 Revised: 14 April 2010

Accepted: 27 May 2010 Published: 27 May 2010

\section{References}

1. Vincent JL, Rello J, Marshall J, Silva E, Anzueto A, Martin CD, Moreno R, Lipman J, Gomersall C, Sakr Y, Reinhart K, EPIC II Group of Investigators: International study of the prevalence and outcomes of infection in intensive care units. JAMA 2009, 302:2323-2329.

2. Morrell M, Fraser VJ, Kollef MH: Delaying the empiric treatment of Candida bloodstream infection until positive blood culture results are obtained: a potential risk factor for hospital mortality. Antimicrob Agents Chemother 2005, 49:3640-3645.

3. Parkins MD, Sabuda DM, Elsayed S, Laupland KB: Adequacy of empirical antifungal therapy and effect on outcome among patients with invasive Candida species infections. J Antimicrob Chemother 2007, 60:613-618

4. Garey KW, Rege M, Pai MP, Mingo DE, Suda KJ, Turpin RS, Bearden DT: Time to initiation of fluconazole therapy impacts mortality in patients with candidemia: a multi-institutional study. Clin Infect Dis 2006, 43:25-31.

5. Leroy O, Gangneux JP, Montravers P, Mira JP, Gouin F, Sollet JP, Carlet J, Reynes J, Rosenheim M, Regnier B, Lortholary O, AmarCand Study Group: Epidemiology, management, and risk factors for death of invasive Candida infections in critical care: a multicenter, prospective, observational study in France (2005-2006). Crit Care Med 2009, 37:1612-1618.

6. Leroy O, Mira JP, Montravers P, Gangneux JP, Gouin F, Sollet JP, Carlet J, Reynes J, Rosenheim M, Regnier B, Lortholary O, AmarCand Study Group: [Invasive candidiasis in ICU: analysis of antifungal treatments in the French study AmarCand]. Ann Fr Anesth Reanim 2008, 27:999-1007.

7. Ascioglu S, Rex JH, de Pauw B, Bennett JE, Bille J, Crokaert F, Denning DW, Donnelly JP, Edwards JE, Erjavec Z, Fiere D, Lortholary O, Maertens J, Meis JF, Patterson TF, Ritter J, Selleslag D, Shah PM, Stevens DA, Walsh TJ, Invasive Fungal Infections Cooperative Group of the European Organization for Research and Treatment of Cancer, Mycoses Study Group of the National Institute of Allergy and Infectious Diseases: Defining opportunistic invasive fungal infections in immunocompromised patients with cancer and hematopoietic stem cell transplants: an international consensus. Clin Infect Dis 2002, 34:7-14. 
8. Clinical and laboratory standards institute Antifungal susceptibility testing [http://www.clsi.org/source/orders/categories.cfm?section= Antifungal Susceptibility Testing\&CAT=ANTIFUNGAL].

9. Cheng MF, Yang YL, Yao TJ, Lin CY, Liu JS, Tang RB, Yu KW, Fan YH, Hsieh KS, Ho M, Lo HJ: Risk factors for fatal candidemia caused by Candida albicans and non-albicans Candida species. BMC Infect Dis 2005, 5:22.

10. Shorr AF, Lazarus DR, Sherner JH, Jackson WL, Morrel M, Fraser VJ, Kollef $\mathrm{MH}$ : Do clinical features allow for accurate prediction of fungal pathogenesis in bloodstream infections? Potential implications of the increasing prevalence of non-albicans candidemia. Crit Care Med 2007 35:1077-1083

11. Horn DL, Neofytos D, Anaissie EJ, Fishman JA, Steinbach WJ, Olyaei AJ, Marr KA, Pfaller MA, Chang CH, Webster KM: Epidemiology and outcomes of candidemia in 2019 patients: data from the prospective antifungal therapy alliance registry. Clin Infect Dis 2009, 48:1695-1703.

12. Playford EG, Marriott D, Nguyen Q, Chen S, Ellis D, Slavin M, Sorrell TC: Candidemia in nonneutropenic critically ill patients: risk factors for non-albicans Candida spp. Crit Care Med 2008, 36:2034-2039.

13. Chow JK, Golan Y, Ruthazer R, Karchmer AW, Carmeli Y, Lichtenberg D, Chawla V, Young J, Hadley S: Factors associated with candidemia caused by non-albicans Candida species versus Candida albicans in the intensive care unit. Clin Infect Dis 2008, 46:1206-1213.

14. Holley A, Dulhunty J, Blot S, Lipman J, Lobo S, Dancer C, Rello J, Dimopoulos G: Temporal trends, risk factors and outcomes in albicans and non-albicans candidaemia: an international epidemiological study in four multidisciplinary intensive care units. Int $J$ Antimicrob Agents 2009, 33:554.

15. Société Française d'Anesthésie et de Réanimation Société de Pathologie Infectieuse de Langue Française Société de Réanimation de Langue Française Société Française d'Hématologie Société Française de Mycologie Médicale Société Française de Greffe de Mœlle (Consensus Conference): Management of invasive candidiasis and aspergillosis in adults. Rev Pneumol Clin 2004, 60:289-293.

16. Pappas PG, Kauffman CA, Andes D, Benjamin DK Jr, Calandra TF, Edwards JE Jr, Filler SG, Fisher JF, Kullberg BJ, Ostrosky-Zeichner L, Reboli AC, Rex JH, Walsh TJ, Sobel JD, Infectious Diseases Society of America: Clinical practice guidelines for the management of candidiasis: 2009 update by the Infectious Diseases Society of America. Clin Infect Dis 2009, 48:503-535

17. McCabe W, Jackson G: Gram-negative bacteremia: etiology and ecology. Arch Intern Med 1962, 110:847-855.

doi: $10.1186 /$ cc9033

Cite this article as: Leroy et al., Comparison of albicans vs. non-albicans candidemia in French intensive care units Critical Care 2010, 14:R98

Submit your next manuscript to BioMed Centra and take full advantage of:

- Convenient online submission

- Thorough peer review

- No space constraints or color figure charges

- Immediate publication on acceptance

- Inclusion in PubMed, CAS, Scopus and Google Scholar

- Research which is freely available for redistribution

Submit your manuscript at www.biomedcentral.com/submit
C Biomed Central 